\section{OPEN ACCESS}

Edited by:

Lucio Vilar,

Federal University of

Pernambuco, Brazi

Reviewed by:

Michio Otsuki,

Osaka University Hospital, Japan

Rosario Pivonello,

University of Naples Federico II, Italy

${ }^{*}$ Correspondence:

Maria Fleseriu

fleseriu@ohsu.edu

Specialty section: This article was submitted to

Pituitary Endocrinology,

a section of the journal

Frontiers in Endocrinology

Received: 05 March 2019 Accepted: 18 June 2019

Published: 16 July 2019

Citation:

Fleseriu M, Iweha C, Salgado L,

Mazzuco TL, Campigotto F, Maamari $R$ and Limumpornpetch $P$

(2019) Safety and Efficacy of Subcutaneous Pasireotide in Patients With Cushing's Disease: Results From

an Open-Label, Multicenter Single-Arm, Multinational,

Expanded-Access Study.

Front. Endocrinol. 10:436

doi: 10.3389/fendo.2019.00436

\title{
Safety and Efficacy of Subcutaneous Pasireotide in Patients With Cushing's Disease: Results From an Open-Label, Multicenter, Single-Arm, Multinational, Expanded-Access Study
}

Maria Fleseriu ${ }^{1 *}$, Chioma Iweha ${ }^{2}$, Luiz Salgado ${ }^{3}$, Tania Longo Mazzuco ${ }^{4}$, Federico Campigotto ${ }^{5}$, Ricardo Maamari ${ }^{5}$ and Padiporn Limumpornpetch ${ }^{6}$

${ }^{1}$ Departments of Medicine and Neurological Surgery, Northwest Pituitary Center, Oregon Health and Science University, Portland, OR, United States, ${ }^{2}$ Panda Medical Associates, Peoria, AZ, United States, ${ }^{3}$ General Internal Medicine Service, Hospital das Clinicas da Faculdade de Medicina FMUSP, São Paulo, Brazil, ${ }^{4}$ Division of Endocrinology of Medical Clinical Department, University Hospital, UEL, Londrina, Brazil, ${ }^{5}$ Novartis Pharmaceuticals Corporation, East Hanover, NJ, United States, ${ }^{6}$ Division of Endocrinology and Metabolism, Department of Internal Medicine, Faculty of Medicine, Prince of Songkla University, Hat Yai, Thailand

Introduction: The efficacy and safety of subcutaneous (sc) pasireotide have been evaluated in a Phase III trial. Here, we report safety and efficacy results from a multinational, expanded-access study of pasireotide sc in patients with Cushing's disease (CD) in a real-world setting (clinicaltrials.gov, identifier: NCT01582061).

Methods: Adults with active CD previously untreated with pasireotide were enrolled; pasireotide sc was initiated at $600 \mu \mathrm{g}$ twice daily (bid; EU countries) or $900 \mu \mathrm{g}$ bid (non-EU countries; $600 \mu \mathrm{g}$ bid in patients with impaired glucose metabolism). Pasireotide dose could be adjusted in $300 \mu \mathrm{g}$ increments/decrements to a maximum of $900 \mu \mathrm{g}$ bid or minimum of $300 \mu \mathrm{g}$ bid for sustained urinary free cortisol (UFC) normalization/tolerability issues. Primary objective: document the safety of pasireotide Sc in patients with CD. Key secondary objectives: assess the proportion of patients with mean UFC (mUFC) not exceeding the upper limit of normal (ULN) and changes from baseline in clinical signs/symptoms and quality of life (QoL) to weeks 12, 24, and 48.

Results: One hundred and four patients received pasireotide: female, $n=84$ (80.8\%); median duration of pasireotide exposure, 25.1 weeks; median (range) baseline mUFC, $321.2 \mathrm{nmol} / 24 \mathrm{~h}(142-10,920 ; 2.3 \times$ ULN [1.0-79.2]). Forty (38.5\%) patients completed the study. The most common reasons for premature discontinuation of pasireotide were unsatisfactory therapeutic effect $(n=26,25.0 \%)$ and adverse events (AEs; $n=20$, 19.2\%). Drug-related grade 3/4 AEs or drug-related serious AEs (primary endpoint) were documented in 42 (40.4\%) patients, most commonly diabetes mellitus ( $n=12,11.5 \%)$ and hyperglycemia $(n=8,7.7 \%)$. All patients experienced $\geq 1$ AE and most $(n=102$; 98.1\%) reported $\geq 1$ drug-related $A E$; six (5.8\%) patients discontinued treatment because of hyperglycemia-related AEs. At weeks 12, 24, and 48, respectively, 36/66 (54.5\%), 
22/46 (47.8\%), and 9/21 (42.9\%) evaluable patients had normalized mUFC levels. Clinical signs/symptoms and QoL were also improved.

Conclusions: In an international, real-world, clinical-practice setting, pasireotide sc was generally well-tolerated (no new safety signals were identified), effectively reduced UFC (normalization in 50\% of evaluable patients) and improved clinical signs and QoL in patients with $C D$. While hyperglycemia-related AEs were common, consistent with previous studies, most were manageable, with $<6 \%$ of patients discontinuing treatment because of these events.

Keywords: Cushing's disease, pasireotide sc, somatostatin analog, clinical practice, real world

\section{INTRODUCTION}

Cushing's disease is a rare and serious endocrine disorder characterized by a pituitary tumor (corticotropinoma) that secretes an excess of adrenocorticotropic hormone (ACTH), with consequent overproduction of cortisol from the adrenal glands (1). Sustained hypercortisolism is associated with significant morbidity, which includes, but is not restricted to, central obesity, diabetes mellitus, dyslipidemia and hypertension; prolonged exposure to elevated cortisol levels, and the associated comorbidities, may also cause impairment of quality of life (QoL) and premature mortality (2-4).

The goals of treatment are to normalize cortisol levels (5), with suppression of hypercortisolism shown to reverse signs and symptoms, alleviate the burden of morbidity, and reduce mortality $(1,4,6-8)$. Surgical removal of the pituitary tumor is the first-line treatment for most patients with Cushing's disease (5). However, patients may fail to respond or experience disease recurrence $(9,10)$. A pooled analysis of a series of studies showed mean remission and recurrence rates after surgery of 82 and $12 \%$, respectively, for patients with a microadenoma and 62 and $19 \%$ for patients with a macroadenoma (8). As such, effective alternative treatment strategies are required. Bilateral adrenalectomy can result in complete resolution of hypercortisolism, but it renders patients glucocorticoid and mineralocorticoid deficient and may also lead to corticotroph tumor progression (Nelson's syndrome), which is characterized by pituitary tumor expansion coupled with high ACTH concentrations (11). Radiotherapy can also be efficacious in some patients, but maximum clinical benefit is typically only achieved years after treatment initiation (11). Current medical therapies used for the treatment of Cushing's disease include adrenal-directed agents such as ketoconazole, metyrapone (both approved in the EU) and mitotane, the glucocorticoid receptor antagonist mifepristone (approved in the USA for the management of hyperglycemia associated with Cushing's syndrome), and the pituitary-targeted drugs cabergoline and pasireotide, of which the latter (twicedaily [bid] subcutaneous [sc] formulation) is approved in both the USA and the EU $(5,12)$. Recently, a longacting formulation of pasireotide suitable for once-monthly administration has been approved in the EU, Japan, Canada, and the USA.
Pasireotide is a multireceptor-targeted somatostatin analog that binds to four of the five somatostatin receptor subtypes, with the highest affinity for subtype 5 (13-15). In a large Phase III study in patients with Cushing's disease $(N=162)$, pasireotide sc bid induced rapid and sustained reductions in mean $24 \mathrm{~h}$ urinary free cortisol (mUFC) levels, with patients also benefiting from improvements in signs and symptoms of Cushing's disease and QoL (16). Pasireotide sc was generally well-tolerated; although hyperglycemia-related adverse events (AEs) were reported in $73 \%$ of patients, only $6 \%$ of patients had pasireotide withdrawn because of these events.

While the efficacy and safety of pasireotide sc have been established in randomized, prospective studies, few studies have evaluated pasireotide sc in patients with Cushing's disease in real-world clinical practice (17-20). Here, we describe safety and efficacy results of an international, real-world study of pasireotide sc in a large population $(N=104)$ of patients with Cushing's disease in clinical practice.

\section{METHODS}

\section{Patients}

Adult patients ( $\geq 18$ years old) with persistent or recurrent Cushing's disease, or de novo patients not considered candidates for surgery, were recruited. Patients must have had active disease, as evidenced by: mean of three $24 \mathrm{~h}$ UFC samples collected during a 3-week screening period above the upper limit of normal (ULN; $137.95 \mathrm{nmol} / 24 \mathrm{~h}$ ), which was determined from a central laboratory reference; morning plasma ACTH within or above the normal range; and confirmed pituitary source of the disease. For patients on previous medical treatment for Cushing's disease, the following washout periods were required prior to screening assessments: mitotane, 6 months; long-acting octreotide, lanreotide Autogel, 8 weeks; dopamine agonists (bromocriptine, cabergoline), mifepristone, lanreotide sustained release, 4 weeks; steroidogenesis inhibitors (ketoconazole, metyrapone, rosiglitazone), octreotide immediate release, 1 week.

Patients were excluded from the study if they had any of the following criteria: prior exposure to pasireotide sc; radiotherapy $<4$ weeks before screening; tumor compressing the optic chiasm, causing visual field defects; symptomatic cholelithiasis; diabetes with poorly controlled blood glucose levels (glycated 
hemoglobin $\left[\mathrm{HbA}_{1 \mathrm{c}}\right]>8 \%$ ); QTcF $>450 \mathrm{~ms}$ at screening and any other clinically significant impairment of cardiovascular function; pregnancy.

\section{Study Design}

This was an open-label, single-arm, multicenter, expandedaccess study.

After a 21-day screening period, enrolled patients in EU countries received pasireotide sc starting doses of $900 \mu \mathrm{g}$ bid; the study protocol was amended in 2013 (patient enrollment began in 2011) so that all EU patients received starting doses of 600 $\mu \mathrm{g}$ bid to align with the recommendation by the Committee for Medicinal Products for Human Use and the European Medicines Agency that the starting dose of pasireotide sc should be $600 \mu \mathrm{g}$ bid (21). Patients in non-EU countries received starting doses of $900 \mu \mathrm{g}$ bid $(600 \mu \mathrm{g}$ bid in patients with impaired glucose metabolism). The dose could be increased (after $>2$ months' treatment if UFC was not controlled) or decreased (for sustained UFC normalization/tolerability issues) in $300 \mu \mathrm{g}$ increments or decrements to a maximum of $900 \mu \mathrm{g}$ bid or a minimum of $300 \mu \mathrm{g}$ bid.

Patients received treatment until pasireotide sc was approved for commercial use and reimbursed in each respective country or until December 31, 2015 (December 31, 2016 for sites in South Korea and Brazil), whichever occurred first.

\section{Objectives and Assessments}

The primary objective of the study was to document the safety of pasireotide sc; the primary endpoint was the proportion of patients with drug-related grade 3/4 AEs or drug-related serious AEs (SAEs). Key secondary endpoints, which were assessed at weeks 12, 24, and 48, included: proportion of patients with mUFC $\leq \mathrm{ULN}$; proportion of patients achieving at least $50 \%$ reduction from baseline in mUFC; changes from baseline in clinical signs and symptoms; and changes from baseline in health-related QoL (HRQoL).

Monitoring of safety throughout the study was carried out by performing standard safety assessments (including laboratory, vital signs, and electrocardiography evaluations) for patients with Cushing's disease and the recording of AEs at each visit. For the primary endpoint, the severity of AEs was defined as mild (grade 1), moderate (grade 2), severe (grade 3), and life threatening or debilitating (grade 4) according to the National Cancer Institute's Common Terminology Criteria for Adverse Events (CTCAE) version 3.0 (22). If CTCAE grading did not exist for an $\mathrm{AE}$, the severity of mild, moderate, severe, and life threatening, corresponding to grades $1-4$, was used. CTCAE grade 5 (death) was not used in this study; information about deaths was collected through a cause-of-death form. SAEs were defined as one of the following: fatal or life threatening; resulting in persistent or significant disability/incapacity; constituting a congenital anomaly/birth defect; medically significant (defined as an event that jeopardizes the patient or may require medical or surgical intervention to prevent one of the aforementioned outcomes); requiring or prolonging hospitalization.

Measurement of mUFC was determined at 4-weekly intervals until week 24; from week 24 onwards, patients were assessed at 12 -week intervals. mUFC was calculated from three $24 \mathrm{~h}$
UFC measurements (collected during the week before visits) at weeks 12, 24, and 48 and from two $24 \mathrm{~h}$ UFC measurements (collected on two consecutive days before visits) at weeks 4, 8, 16, and 20. Clinical signs and symptoms, including sitting systolic and diastolic blood pressure (BP), weight, waist circumference, facial rubor, striae, bruising, hirsutism, muscle strength, and supraclavicular and dorsal fat pads, were assessed at every study visit. Facial rubor, striae, bruising, muscle strength, and supraclavicular and dorsal fat pads were assessed by the investigator; hirsutism (females only) was assessed by the Ferriman-Gallway score. Patients' QoL was assessed by the patients at weeks 4, 12, 24, 36, and 48 using a standardized 12-item Cushing's syndrome HRQoL questionnaire (CushingQoL) (23).

\section{Statistical Analyses}

Demographics and other baseline characteristics are summarized descriptively. Categorical data are presented as frequencies and percentages. For continuous data, mean and standard deviation (SD) or median and range are described. Safety assessments were performed on all patients who received at least one dose of pasireotide sc and had at least one post-baseline safety assessment and are summarized descriptively. Treatment-emergent AEs include only AEs that started or worsened during the ontreatment period up to 28 days after discontinuation of the study drug.

Secondary efficacy assessments were performed on all patients who received at least one dose of pasireotide sc and are summarized descriptively with corresponding two-sided 95\% exact confidence intervals (CIs) for weeks 12, 24, and 48. Patients were divided into two groups based on mean actual daily dose: $600 \mu \mathrm{g}$ bid, all patients whose mean daily dose during the study was $<1,500 \mu \mathrm{g} /$ day; $900 \mu \mathrm{g}$ bid, all patients whose mean daily dose was $\geq 1,500 \mu \mathrm{g} /$ day during the study.

\section{RESULTS}

\section{Baseline Demographics and Characteristics}

One hundred and four eligible patients (600 $\mu \mathrm{g}$ bid, $n=49$; $900 \mu \mathrm{g}$ bid, $n=55$ ) from 81 centers in 12 countries received pasireotide sc between August 16, 2011 and January 26, 2017 (Table 1). Median (range) baseline UFC level for all patients was $321.2 \mathrm{nmol} / 24 \mathrm{~h}(142-10,920 ; 2.3 \times$ ULN [1.0-79.2]). Median (range) baseline UFC level for the $600 \mu \mathrm{g}$ group was 255.6 $\mathrm{nmol} / 24 \mathrm{~h}(142-10,920 ; 1.9 \times \mathrm{ULN}[1.0-79.2])$ and for the 900 $\mu \mathrm{g}$ cohort was $452.0 \mathrm{nmol} / 24 \mathrm{~h}(143-3,991 ; 3.3 \times$ ULN [1.028.9]). Overall, most patients $(n=98 ; 94.2 \%)$ had at least one current medical condition at baseline; the most common $(>15 \%)$ were hypertension $(n=62 ; 59.6 \%)$, hypothyroidism $(n=21$; $20.2 \%)$, dyslipidemia $(n=20 ; 19.2 \%)$ and diabetes mellitus $(n=16 ; 15.4 \%)$. Eighty-four $(80.8 \%)$ patients had received prior pituitary surgery at baseline, and $53(51.0 \%)$ had been treated with medical therapy.

In total, $64(61.5 \%)$ patients discontinued treatment, 28/49 (57.1\%) in the $600 \mu \mathrm{g}$ group and 36/55 (65.5\%) in the 900 $\mu \mathrm{g}$ cohort; the reasons for discontinuation were unsatisfactory therapeutic effect $(n=26 ; 25.0 \%)$, AEs $(n=20 ; 19.2 \%)$, subject 
TABLE 1 | Patient baseline characteristics and demographics.

\begin{tabular}{|c|c|c|c|}
\hline & $\begin{array}{l}\text { Pasireotide } 600 \mu \mathrm{g} \\
\quad \text { bid } N=49\end{array}$ & $\begin{array}{l}\text { Pasireotide } 900 \mu \mathrm{g} \\
\quad \text { bid } N=55\end{array}$ & $\begin{array}{l}\text { All patients } \\
\qquad N=104\end{array}$ \\
\hline Mean age, years (SD) & $45.5(13.1)$ & $39.9(12.6)$ & $42.5(13.1)$ \\
\hline \multicolumn{4}{|l|}{ Race, $n(\%)$} \\
\hline Caucasian & 39 (79.6) & $36(65.5)$ & $75(72.1)$ \\
\hline Other & $1(2.0)$ & 2 (3.6) & $3(2.9)$ \\
\hline $\begin{array}{l}\text { Median time from diagnosis to first pasireotide dose, months } \\
\text { (range) }\end{array}$ & $60.3(0.7-309.0)$ & $34.3(1.0-298.0)$ & $39.7(0.7-309.0)$ \\
\hline \multicolumn{4}{|l|}{ Cushing's disease status, $n(\%)$} \\
\hline De novo & 8 (16.3) & $5(9.1)$ & $13(12.5)$ \\
\hline Missing & $8(16.3)$ & $5(9.1)$ & $13(12.5)$ \\
\hline $\begin{array}{l}\text { Median time from previous surgery to first pasireotide dose, } \\
\text { months (range) }\end{array}$ & $44.8(4.1-306.1)$ & $30.5(1.9-294.1)$ & $38.1(1.9-306.1)$ \\
\hline \multicolumn{4}{|l|}{ Prior pituitary irradiation, $n(\%)$} \\
\hline Yes & $12(24.5)$ & $15(27.3)$ & $27(26.0)$ \\
\hline No & $37(75.5)$ & $40(72.7)$ & $77(74.0)$ \\
\hline $\begin{array}{l}\text { Median time from last pituitary irradiation to first pasireotide } \\
\text { dose, months (range) }\end{array}$ & $56.9(8.5-169.9)$ & $29.0(3.1-205.8)$ & $33.3(3.1-205.8)$ \\
\hline
\end{tabular}

withdrew consent ( $n=14 ; 13.5 \%$ ), abnormal laboratory value(s), death, condition no longer required study drug, and loss to follow-up (all $n=1 ; 1 \%)$.

\section{Treatment Exposure}

Median (range) duration of pasireotide sc exposure from initiation was 25.1 weeks (1-256.4); 82 (78.8\%) patients received treatment for $\geq 12$ weeks, 55 (52.9\%) were treated for $\geq 24$ weeks, and $36(34.6 \%)$ were treated for $\geq 48$ weeks. Median (range) exposure to pasireotide in all patients who discontinued treatment prematurely $(N=64)$ was 20.7 weeks (1.3-204.0) and in those who discontinued pasireotide prematurely because of AEs $(N=20)$ was 6.9 weeks (1.3-77.1).

Patients received a mean (SD) dose intensity of 1421.0 $\mu \mathrm{g} /$ day (390.1). Mean (SD) dose intensity in all patients who discontinued treatment prematurely was $1442.4 \mu \mathrm{g} /$ day (380.3) and in those who discontinued treatment prematurely because of AEs was $1239.4 \mu \mathrm{g} /$ day (428.5). Sixty-six (63.5\%) patients had a change in dose intensity, and 28 (26.9\%) patients required a dose interruption; AEs/laboratory abnormalities were the most common reason for a change in dose intensity $(n=22 ; 21.2 \%)$ and dose interruption $(n=23 ; 22.1 \%)$. Pasireotide exposure overall and by dose group is reported in Table 2.

\section{Safety}

Overall, most treatment-emergent AEs were mild to moderate in severity, with $42(40.4 \%)$ patients experiencing drugrelated grade $3 / 4$ AEs or drug-related SAEs (primary endpoint), $26(53.1 \%)$ in the $600 \mu \mathrm{g}$ group and $16(29.1 \%)$ in the $900 \mu \mathrm{g}$ cohort; the most common by system organ class were metabolism/nutritional $(n=20 ; 19.2 \%)$ and gastrointestinal $(n=13,12.5 \%)$ disorders, and by preferred term were diabetes mellitus $(n=12 ; 11.5 \%)$ and hyperglycemia ( $n=8 ; 7.7 \%)$ (Table 3).

All patients had at least one treatment-emergent $\mathrm{AE}$, regardless of relationship to drug, of which diarrhea $(n=53$; $51.0 \%)$, nausea $(n=48 ; 46.2 \%)$, hyperglycemia $(n=42 ; 40.4 \%)$, headache $(n=31 ; 29.8 \%)$, cholelithiasis $(n=30 ; 28.8 \%)$, diabetes mellitus $(n=25 ; 24.0 \%)$ and fatigue $(n=23 ; 22.1 \%)$ were the most common ( $\geq 20 \%$ in all patients). Furthermore, most patients $(n=102 ; 98.1 \%)$ had at least one AE considered to be drug related (Table 4), with grade $3 / 4$ drug-related AEs observed in $41(39.4 \%)$ patients, the most frequent being diabetes mellitus $(n=11 ; 10.6 \%)$ and hyperglycemia $(n=8 ; 7.7 \%)$.

Overall, $30(28.8 \%)$ patients had treatment-emergent SAEs, regardless of relationship to drug, with acute cholecystitis, diabetes mellitus and diarrhea the most common (all $n=3$; $2.9 \%)$. SAEs considered drug related were observed in $16(15.4 \%)$ patients, $10(20.4 \%)$ in the $600 \mu \mathrm{g}$ group and six (10.9\%) in the $900 \mu \mathrm{g}$ cohort.

Twenty (19.2\%) patients discontinued treatment because of AEs (600 $\mu \mathrm{g}, n=12$ [24.5\%]; $900 \mu \mathrm{g}, n=8$ [14.5\%]). Only six patients discontinued because of hyperglycemia-related AEs (grade 2, $n=3$; grade $3, n=2$; grade $4, n=1$ ), the most common AEs leading to treatment withdrawal: five (10.2\%) in the 600 $\mu \mathrm{g}$ cohort and one $(1.8 \%)$ in the $900 \mu \mathrm{g}$ group. Gastrointestinal disorders also led to treatment withdrawal in six (5.8\%) patients 
TABLE 2 | Pasireotide exposure overall and by dose level.

\begin{tabular}{|c|c|c|c|}
\hline & Pasireotide $600 \mu \mathrm{g}$ bid $N=49$ & Pasireotide $900 \mu \mathrm{g}$ bid $N=55$ & All patients $N=104$ \\
\hline Median duration of exposure, weeks (range) & $24.3(1-185)$ & $26.0(3-256)$ & $25.1(1-256)$ \\
\hline \multicolumn{4}{|l|}{ Duration of exposure category, $n(\%)$} \\
\hline$<12$ weeks & $13(26.5)$ & $9(16.4)$ & $22(21.2)$ \\
\hline $12-<24$ weeks & $11(22.4)$ & $16(29.1)$ & $27(26.0)$ \\
\hline $24-<36$ weeks & $7(14.3)$ & $7(12.7)$ & $14(13.5)$ \\
\hline Mean dose intensity, $\mu \mathrm{g} /$ day (SD) & $1066.5(245.3)$ & $1736.8(145.7)$ & $1421.0(390.1)$ \\
\hline Number of dose changes, $\mathrm{n}$ & 41 & 25 & 66 \\
\hline Mean (SD) & $3.6(3.7)$ & $3.6(5.2)$ & $3.6(4.3)$ \\
\hline Median (range) & $2.0(1.0-16.0)$ & $2.0(1.0-25.0)$ & $2.0(1.0-25.0)$ \\
\hline Number of dose interruptions, $\mathrm{n}$ & 18 & 10 & 28 \\
\hline
\end{tabular}

TABLE 3 | Patients who had drug-related grade 3/4 AEs or drug-related SAEs $(>1 \%$ in all patients) by preferred term and dose group.

\begin{tabular}{|c|c|c|c|}
\hline Preferred term & $\begin{array}{c}\text { Pasireotide } 600 \\
\mu \mathrm{g} \text { bid } N=49 \\
n(\%)\end{array}$ & $\begin{array}{c}\text { Pasireotide } 900 \\
\mu \mathrm{g} \text { bid } N=55 \\
n(\%)\end{array}$ & $\begin{array}{c}\text { All patients } \\
N=104 \\
n(\%)\end{array}$ \\
\hline Total & $26(53.1)$ & $16(29.1)$ & $42(40.4)$ \\
\hline Diabetes mellitus & $6(12.2)$ & $6(10.9)$ & $12(11.5)$ \\
\hline Hyperglycemia & $7(14.3)$ & $1(1.8)$ & $8(7.7)$ \\
\hline Diarrhea & $4(8.2)$ & $1(1.8)$ & $5(4.8)$ \\
\hline Nausea & $3(6.1)$ & $2(3.6)$ & $5(4.8)$ \\
\hline Blood cortisol decreased & $2(4.1)$ & $1(1.8)$ & $3(2.9)$ \\
\hline Cholecystitis acute & 0 & $3(5.5)$ & $3(2.9)$ \\
\hline Adrenal insufficiency & $2(4.1)$ & 0 & $2(1.9)$ \\
\hline
\end{tabular}

(600 $\mu \mathrm{g}, n=5$ [10.2\%]; $900 \mu \mathrm{g}, n=1$ [1.8\%]), with abdominal pain and diarrhea the most common (both $n=2 ; 1.9 \%$ ).

Hyperglycemia-related AEs were documented in 79 (76.0\%) patients overall, with the incidence of these AEs similar between dose groups (600 $\mu \mathrm{g}, n=35$ [71.4\%]; $900 \mu \mathrm{g}, n=44$ [80.0\%)]. The majority of hyperglycemia-related AEs were suspected to be drug related $(n=75 ; 72.1 \%)$, and most were of mild-tomoderate severity, with 19 (18.3\%) patients experiencing these AEs at grade $3 / 4$ severity (600 $\mu \mathrm{g}, n=13$ [26.5\%]; $900 \mu \mathrm{g}$, $n=6[10.9 \%])$ and six (5.8\%) patients reporting these events as SAEs. Of the six patients with hyperglycemia-related SAEs, two had the events resolve with dose adjustment/interruption and three discontinued treatment. There were no instances of diabetic ketoacidosis or hyperosmolar hyperglycemia. Most patients with hyperglycemia-related AEs had a medical history of obesity, dyslipidemia, increased blood glucose, hyperinsulinemia and/or diabetes mellitus. At baseline, 73/104 (70.2\%) and 63/104 (60.6\%) patients, respectively, had fasting plasma glucose (FPG) and $\mathrm{HbA}_{1 \mathrm{c}}$ levels in the normal range (FPG $<100 \mathrm{mg} / \mathrm{dL}$; $\left.\mathrm{HbA}_{1 \mathrm{c}}<5.7 \%\right)$. Of these patients, last post-baseline FPG and $\mathrm{HbA}_{1 \mathrm{c}}$ levels were in the diabetic range $(\mathrm{FPG} \geq 126 \mathrm{mg} / \mathrm{dL}$;
$\left.\mathrm{HbA}_{1 \mathrm{c}} \geq 6.5 \%\right)$ in $25 / 73(34.2 \%)$ and $19 / 63$ (30.2\%) patients. Of patients with prediabetic levels of FPG $(100-<126 \mathrm{mg} / \mathrm{dL} ; n=$ 24/104 [23.1\%]) and $\mathrm{HbA}_{1 \mathrm{c}}(5.7-<6.5 \% ; n=21 / 104$ [20.2\%]) at baseline, $16 / 24(66.7 \%)$ and $17 / 21$ (80.9\%), respectively, had last post-baseline levels in the diabetic range. Overall, 61/104 (58.7\%) and 51/104 (49.0\%) patients, respectively, had last post-baseline FPG and $\mathrm{HbA}_{1 \mathrm{c}}$ levels within the normal/prediabetic range. Shifts in FPG and $\mathrm{HbA}_{1 \mathrm{c}}$ levels from baseline to last post-baseline value according to diabetic status are shown in Table 5 .

Gallbladder- and biliary-related AEs were documented in $32(30.8 \%)$ patients, with cholelithiasis $(n=30 ; 28.8 \%)$ the most common (Table 6); none of these AEs led to treatment discontinuation. One patient required surgery for an AE of cholelithiasis. Other AEs of special interest included hypocortisolism-related AEs, recorded in eight (7.7\%) patients (Table 6). In five patients for whom additional information was provided by the investigator, nine hypocortisolism-related AEs were reported: adrenal insufficiency $(n=4$ [grade $2, n=1$; grade $3, n=3$ ], blood cortisol decreased ( $n=3$ [all grade 3 ], glucocorticoid deficiency $(n=1$ [grade 3 ] and cortisol free urine decreased ( $n=1$ [grade 2]. Of the nine hypercortisolismrelated AEs, six had resolved at the patient's last assessment, three after reduction of the pasireotide dose, two after initiation of glucocorticoid supplementation and reduction/interruption of the pasireotide dose, and one after discontinuation of pasireotide treatment.

Most patients experienced an $\mathrm{AE}$ that required additional therapy ( $n=91 ; 87.5 \%)$, with 81 (77.9\%) patients requiring additional therapy to manage an $\mathrm{AE}$ that was suspected to be related to pasireotide treatment (Table 7); hyperglycemia was the most common AE requiring additional therapy $(n=31 ; 29.8 \%)$. Various glucose-lowering drugs were used for the management of hyperglycemia, including metformin $(n=40,38.5 \%)$, metformin hydrochloride ( $n=12,11.5 \%)$, dipeptidyl peptidase-4 (DPP-4) inhibitors ( $n=20,19.2 \%$; primarily vildagliptin $[n=7,6.7 \%]$ and sitagliptin phosphate $[n=6,5.8 \%])$, sulfonylureas $(n=20$, $19.2 \%$; primarily gliclazide $[n=8,7.7 \%]$ and glimepiride $[n=7$, 
TABLE 4 | Patients who had drug-related AEs (>10\% in all patients) by preferred term and dose group.

\begin{tabular}{|c|c|c|c|c|c|c|}
\hline \multirow[t]{2}{*}{ Preferred term } & \multicolumn{2}{|c|}{$\begin{array}{c}\text { Pasireotide } 600 \mu \mathrm{g} \text { bid } N=49 \\
n(\%)\end{array}$} & \multicolumn{2}{|c|}{$\begin{array}{c}\text { Pasireotide } 900 \mu \mathrm{g} \text { bid } N=55 \\
n(\%)\end{array}$} & \multicolumn{2}{|c|}{$\begin{array}{c}\text { All patients } N=104 \\
n(\%)\end{array}$} \\
\hline & All grades & Grade 3/4 & All grades & Grade 3/4 & All grades & Grade 3/4 \\
\hline Total & $48(98.0)$ & $26(53.1)$ & $54(98.2)$ & $15(27.3)$ & $102(98.1)$ & $41(39.4)$ \\
\hline Diarrhea & $23(46.9)$ & $4(8.2)$ & $21(38.2)$ & $1(1.8)$ & 44 (42.3) & $5(4.8)$ \\
\hline Nausea & $18(36.7)$ & $3(6.1)$ & $23(41.8)$ & $2(3.6)$ & $41(39.4)$ & $5(4.8)$ \\
\hline Diabetes mellitus & $10(20.4)$ & $6(12.2)$ & $14(25.5)$ & $5(9.1)$ & $24(23.1)$ & $11(10.6)$ \\
\hline Abdominal pain & $9(18.4)$ & $1(2.0)$ & $6(10.9)$ & 0 & $15(14.4)$ & $1(1.0)$ \\
\hline Fatigue & $8(16.3)$ & $1(2.0)$ & $6(10.9)$ & 0 & $14(13.5)$ & $1(1.0)$ \\
\hline Headache & $5(10.2)$ & $1(2.0)$ & $8(14.5)$ & 0 & $13(12.5)$ & $1(1.0)$ \\
\hline Blood glucose increased & $3(6.1)$ & 0 & $9(16.4)$ & 0 & $12(11.5)$ & 0 \\
\hline
\end{tabular}

TABLE $\mathbf{5}$ | Shift in FPG and $\mathrm{HbA}_{1 \mathrm{C}}$ levels from baseline to last post-baseline value according to diabetic status.

\begin{tabular}{|c|c|c|c|c|}
\hline \multicolumn{2}{|l|}{ Baseline value } & \multicolumn{3}{|c|}{ Last post-baseline value } \\
\hline$<100$ mg/dL (normal) & $73(70.2)$ & $33(31.7)$ & $15(14.4)$ & $25(24.0)$ \\
\hline $100-<126$ mg/dL (prediabetic) & $24(23.1)$ & $3(2.9)$ & $5(4.8)$ & $16(15.4)$ \\
\hline$\geq 126$ mg/dL (diabetic) & $7(6.7)$ & $3(2.9)$ & $2(1.9)$ & $2(1.9)$ \\
\hline $\mathbf{H b A}_{1 \mathrm{c}}$ & $n(\%)$ & $\begin{array}{c}<5.7 \% \text { (normal) } \\
n(\%)\end{array}$ & $\begin{array}{c}5.7-<6.5 \% \text { (prediabetic) } \\
n(\%)\end{array}$ & $\begin{array}{c}\geq 6.5 \% \text { (diabetic) } \\
n(\%)\end{array}$ \\
\hline$<5.7 \%$ (normal) & $63(60.6)$ & $13(12.5)$ & $31(29.8)$ & 19 (18.3) \\
\hline $5.7-<6.5 \%$ (prediabetic) & $21(20.2)$ & 0 & $3(2.9)$ & $17(16.3)$ \\
\hline
\end{tabular}

One patient did not have a last post-baseline $\mathrm{HbA}_{1 \mathrm{c}}$ measurement.

6.7\%]), and insulin ( $n=30,28.8 \%)$. One patient died during the study, with the death attributed to a 'natural cause' and not considered related to study treatment.

\section{Efficacy}

Overall, of patients with evaluable UFC measurements at weeks 12 , 24, and 48, respectively, 36/66 (54.5\%), 22/46 (47.8\%), and $9 / 21(42.9 \%)$ had mUFC $\leq \mathrm{ULN}$ at those time points; $39 / 66$ (59.1\%), 23/46 (50.0\%), and 12/21 (57.1\%) patients had a reduction in $\mathrm{mUFC}$ of $\geq 50 \%$ from baseline at these time points (Figure 1). After imputation of last available post-baseline mUFC assessments for patients who had discontinued/missing values, $34 / 86(39.5 \%)$ and $30 / 86(34.9 \%)$ patients had mUFC $\leq \mathrm{ULN}$ at weeks 24 and 48, respectively. Mean (95\% CI) percentage change in mUFC from baseline to weeks 12,24 , and 48 is shown in Table 8.

Overall, continuous signs and symptoms (BP, weight, waist circumference, and hirsutism) were improved at week 12, with improvements sustained through to week 48 (Figure 2). A favorable shift in all studied categorical signs of Cushing's disease (facial rubor, striae, bruising, muscle strength, supraclavicular, and dorsal fat pads) was observed from baseline to last postbaseline assessment overall (Figure 3) and by dose group (Figure 4). QoL also improved, as indicated by the mean (95\% CI) percentage increase from baseline in CushingQoL score of $67.1 \%(30.0,104.3)$ at week $12,82.3 \%(25.2,139.4)$ at week 24 , and $34.4 \%(19.5,49.4)$ at week 48 . Changes in clinical signs and symptoms and HRQoL overall and by dose group are reported in Table 9.

\section{DISCUSSION}

The favorable efficacy and safety profile of pasireotide sc in patients with Cushing's disease has previously been established in a Phase III trial (16). This expanded-access study confirms that pasireotide sc is similarly tolerated in a large population of patients with Cushing's disease in 
TABLE 6 | Patients with gallbladder- and biliary-, hyperglycemia-, and hypocortisolism-related adverse events, regardless of relationship to drug, by preferred term and maximum grade, overall and by dose group.

\begin{tabular}{|c|c|c|c|c|c|c|}
\hline \multirow[t]{2}{*}{ Preferred term } & \multicolumn{2}{|c|}{$\begin{array}{c}\text { Pasireotide } 600 \mu \mathrm{g} \text { bid } N=49 \\
n(\%)\end{array}$} & \multicolumn{2}{|c|}{$\begin{array}{c}\text { Pasireotide } 900 \mu \mathrm{g} \text { bid } N=55 \\
n(\%)\end{array}$} & \multicolumn{2}{|c|}{$\begin{array}{c}\text { All patients } N=104 \\
\mathrm{n}(\%)\end{array}$} \\
\hline & All grades & Grade 3/4 & All grades & Grade 3/4 & All grades & Grade 3/4 \\
\hline Gallbladder and biliary related & $10(20.4)$ & 0 & $22(40.0)$ & $3(5.5)$ & $32(30.8)$ & $3(2.9)$ \\
\hline Cholelithiasis & 8 (16.3) & 0 & $22(40.0)$ & $1(1.8)$ & $30(28.8)$ & $1(1.0)$ \\
\hline Cholecystitis acute & 0 & 0 & $3(5.5)$ & $3(5.5)$ & $3(2.9)$ & $3(2.9)$ \\
\hline Biliary dilatation & $1(2.0)$ & 0 & $1(1.8)$ & 0 & $2(1.9)$ & 0 \\
\hline Bile duct stone & 0 & 0 & $1(1.8)$ & $1(1.8)$ & $1(1.0)$ & $1(1.0)$ \\
\hline Cholecystitis & 0 & 0 & $1(1.8)$ & 0 & $1(1.0)$ & 0 \\
\hline Cholecystitis chronic & 0 & 0 & $1(1.8)$ & 0 & $1(1.0)$ & 0 \\
\hline Gallbladder disorder & $1(2.0)$ & 0 & 0 & 0 & $1(1.0)$ & 0 \\
\hline Hyperbilirubinemia & $1(2.0)$ & 0 & 0 & 0 & $1(1.0)$ & 0 \\
\hline Hyperglycemia related & $35(71.4)$ & $14(28.6)$ & $44(80.0)$ & $7(12.7)$ & 79 (76.0) & $21(20.2)$ \\
\hline Hyperglycemia & $20(40.8)$ & 8 (16.3) & $22(40.0)$ & $1(1.8)$ & $42(40.4)$ & $9(8.7)$ \\
\hline Diabetes mellitus & $10(20.4)$ & $6(12.2)$ & $15(27.3)$ & $6(10.9)$ & $25(24.0)$ & $12(11.5)$ \\
\hline Blood glucose increased & $4(8.2)$ & 0 & $9(16.4)$ & 0 & $13(12.5)$ & 0 \\
\hline Type 2 diabetes & $5(10.2)$ & $1(2.0)$ & $3(5.5)$ & 0 & $8(7.7)$ & $1(1.0)$ \\
\hline $\mathrm{HbA}_{1 \mathrm{c}}$ increased & $1(2.0)$ & 0 & $1(1.8)$ & 0 & $2(1.9)$ & 0 \\
\hline Impaired fasting glucose & $1(2.0)$ & 0 & $1(1.8)$ & 0 & $2(1.9)$ & 0 \\
\hline Blood insulin decreased & 0 & 0 & $1(1.8)$ & 0 & $1(1.0)$ & 0 \\
\hline Glucose tolerance impaired & $1(2.0)$ & 0 & 0 & 0 & $1(1.0)$ & 0 \\
\hline Hypocortisolism related & $7(14.3)$ & $4(8.2)$ & $1(1.8)$ & $1(1.8)$ & $8(7.7)$ & $5(4.8)$ \\
\hline Adrenal insufficiency & $4(8.2)$ & $2(4.1)$ & $1(1.8)$ & 0 & $5(4.8)$ & $2(1.9)$ \\
\hline Blood cortisol decreased & $3(6.1)$ & $2(4.1)$ & $1(1.8)$ & $1(1.8)$ & $4(3.8)$ & $3(2.9)$ \\
\hline Cortisol free urine decreased & $2(4.1)$ & 0 & 0 & 0 & $2(1.9)$ & 0 \\
\hline Glucocorticoid deficiency & $1(2.0)$ & $1(2.0)$ & 0 & 0 & $1(1.0)$ & $1(1.0)$ \\
\hline
\end{tabular}

an international, real-world, clinical-practice setting. Over the course of the study, $40 \%$ of patients experienced drugrelated grade $3 / 4$ or SAEs, the primary endpoint of the study. All patients experienced at least one AE during the study, regardless of relationship to pasireotide, with the most frequent related to gastrointestinal discomfort (reported in $\sim 83 \%$ of patients). Although common, most AEs were manageable, with $<20 \%$ of patients discontinuing treatment for this reason.

Hyperglycemia-related AEs were documented in $76 \%$ of patients, consistent with previous reports of pasireotide sc (16). Notably, few patients reported clinically significant hyperglycemia-related AEs, with grade $3 / 4$ or SAEs of hyperglycemia and diabetes mellitus experienced by 8 and $12 \%$ of patients, respectively; there were no instances of diabetic ketoacidosis or hyperosmolar hyperglycemia observed in the study. Most hyperglycemia-related AEs were manageable, and $<6 \%$ of patients discontinued treatment because of these events. There was no strict protocol for the management of hyperglycemia-related AEs, owing to the observational nature of the study. However, in line with expert recommendations (24), which suggest stepwise management of pasireotide-associated hyperglycemia with metformin followed by the sequential addition of a DPP-4 inhibitor, glucagon-like peptide 1 (GLP-1) agonist and insulin, metformin (39\% of patients) and DPP-4 inhibitors (19\% of patients) were the most frequently used antidiabetic medications in this study. Most patients (79\%) completed $\geq 12$ weeks ( $\geq 3$ months) of treatment, which, given that most glucose elevations typically manifest soon after pasireotide initiation (regardless of baseline glucose status) and peak after 1 month of treatment $(16,25,26)$, suggests that the majority of patients remained on treatment long enough for appropriate treatment decisions to be made regarding management of pasireotide-associated hyperglycemia. Furthermore, glucose levels have been reported to stabilize after their initial rise (25), with the rate and severity of hyperglycemia shown to be mostly unchanged after its initial onset for up to 5 years' treatment with pasireotide sc (26). Impairments in glucose metabolism are common in patients with Cushing's disease, which result from glucocorticoid-related stimulation of gluconeogenesis, as well as increased insulin resistance in the liver and skeletal muscles (4). In this study, 30 and $39 \%$ of patients, respectively, had FPG and $\mathrm{HbA}_{1 \mathrm{c}}$ levels in the prediabetic/diabetic range at baseline $\left(\mathrm{FPG} \geq 100 \mathrm{mg} / \mathrm{dL} ; \mathrm{HbA}_{1 \mathrm{c}}\right.$ $\geq 5.7 \%$ ). It is noteworthy that $59 \%$ and $49 \%$ of patients had a last post-baseline FPG and $\mathrm{HbA}_{1 \mathrm{c}}$ level, respectively, within the normal/prediabetic range (FPG $<126 \mathrm{mg} / \mathrm{dL} ; \mathrm{HbA}_{1 \mathrm{c}}<6.5 \%$ ), and that most patients who reported hyperglycemia-related 
TABLE 7 | Patients with adverse events requiring additional therapy (>2\% all patients), regardless of relationship to drug, by preferred term and maximum grade, overall and by dose group.

\begin{tabular}{|c|c|c|c|c|c|c|}
\hline \multirow[t]{2}{*}{ Preferred term } & \multicolumn{2}{|c|}{$\begin{array}{c}\text { Pasireotide } 600 \mu \mathrm{g} \text { bid } N=49 \\
n(\%)\end{array}$} & \multicolumn{2}{|c|}{$\begin{array}{c}\text { Pasireotide } 900 \mu \mathrm{g} \text { bid } N=55 \\
n(\%)\end{array}$} & \multicolumn{2}{|c|}{$\begin{array}{l}\text { All patients } N=104 \\
n(\%)\end{array}$} \\
\hline & All grades & Grade 3/4 & All grades & Grade $3 / 4$ & All grades & Grade 3/4 \\
\hline Total & $44(89.8)$ & $29(59.2)$ & $47(85.5)$ & $18(32.7)$ & $91(87.5)$ & 47 (45.2) \\
\hline Hyperglycemia & $14(28.6)$ & 8 (16.3) & $17(30.9)$ & $1(1.8)$ & $31(29.8)$ & $9(8.7)$ \\
\hline Diabetes mellitus & $10(20.4)$ & $6(12.2)$ & $13(23.6)$ & $6(10.9)$ & $23(22.1)$ & $12(11.5)$ \\
\hline Nausea & $5(10.2)$ & $3(6.1)$ & $10(18.2)$ & $2(3.6)$ & $15(14.4)$ & $5(4.8)$ \\
\hline Diarrhea & $8(16.3)$ & $3(6.1)$ & $5(9.1)$ & 0 & $13(12.5)$ & $3(2.9)$ \\
\hline Headache & $6(12.2)$ & $1(2.0)$ & $7(12.7)$ & $1(1.8)$ & $13(12.5)$ & $2(1.9)$ \\
\hline Nasopharyngitis & $2(4.1)$ & 0 & $7(12.7)$ & 0 & $9(8.7)$ & 0 \\
\hline Blood glucose increased & $1(2.0)$ & 0 & $6(10.9)$ & 0 & $7(6.7)$ & 0 \\
\hline Type 2 diabetes mellitus & $3(6.1)$ & $1(2.0)$ & $3(5.5)$ & 0 & $6(5.8)$ & $1(1.0)$ \\
\hline Hypertension & $3(6.1)$ & $2(4.1)$ & $3(5.5)$ & $1(1.8)$ & $6(5.8)$ & $3(2.9)$ \\
\hline Abdominal pain & $4(8.2)$ & $1(2.0)$ & $2(3.6)$ & 0 & $6(5.8)$ & $1(1.0)$ \\
\hline Hypokalemia & $1(2.0)$ & $1(2.0)$ & $4(7.3)$ & $2(3.6)$ & $5(4.8)$ & $3(2.9)$ \\
\hline Hypercholesterolemia & $1(2.0)$ & 0 & $3(5.5)$ & 0 & $4(3.8)$ & 0 \\
\hline Back pain & $1(2.0)$ & 0 & $3(5.5)$ & $1(1.8)$ & $4(3.8)$ & $1(1.0)$ \\
\hline Depression & $2(4.1)$ & $1(2.0)$ & $2(3.6)$ & 0 & $4(3.8)$ & $1(1.0)$ \\
\hline Gastroenteritis & $2(4.1)$ & 0 & $2(3.6)$ & 0 & $4(3.8)$ & 0 \\
\hline Urinary tract infection & 0 & 0 & $4(7.3)$ & 0 & $4(3.8)$ & 0 \\
\hline Fatigue & $3(6.1)$ & $1(2.0)$ & $1(1.8)$ & 0 & $4(3.8)$ & $1(1.0)$ \\
\hline Edema peripheral & $2(4.1)$ & $1(2.0)$ & $2(3.6)$ & 0 & $4(3.8)$ & $1(1.0)$ \\
\hline
\end{tabular}

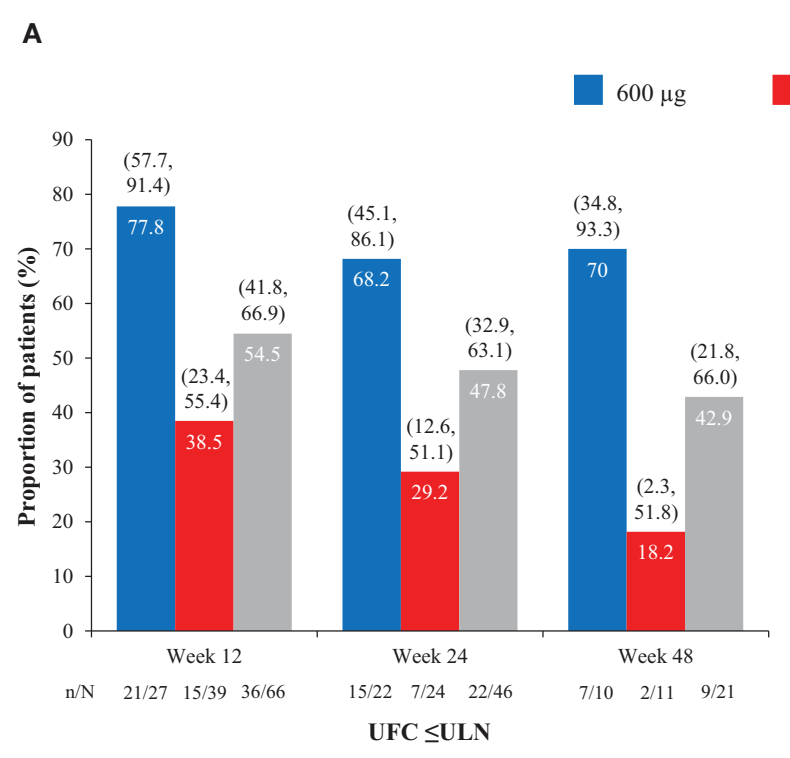

B

$900 \mu \mathrm{g} \quad$ All patients

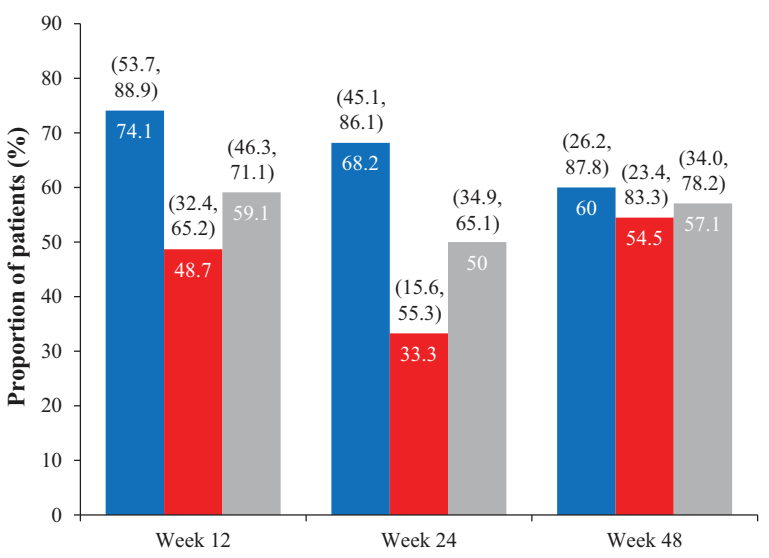

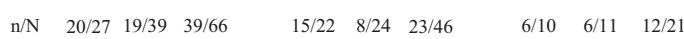

mUFC decrease by $\geq \mathbf{5 0} \%$ from baseline

FIGURE 1 | Proportion of patients with (A) normalized mUFC and (B) a decrease in mUFC of $\geq 50 \%$ from baseline at weeks 12,24 , and 48 , overall and by dose group. Values in parentheses are two-sided $95 \%$ exact Cls.

AEs had prior history of related illness before pasireotide initiation (namely, glucose intolerance or diabetes mellitus, conditions associated with a predisposition to the occurrence of hyperglycemia-related AEs during pasireotide treatment) (25). Furthermore, most patients with normal glucose tolerance at baseline did not have FPG and $\mathrm{HbA}_{1 \mathrm{c}}$ levels in the diabetic range at last post-baseline assessment. This would suggest that control of glucose levels prior to initiation of pasireotide may reduce the likelihood of hyperglycemia occurring during pasireotide treatment. Blood glucose levels need to be closely monitored in patients receiving pasireotide, particularly in patients with pre-existing glucose-related disorders, and glucose-lowering 
TABLE 8 | Mean change in mUFC from baseline to weeks 12, 24, and 48 by dose group.

\begin{tabular}{|c|c|c|c|c|c|c|}
\hline & \multicolumn{2}{|c|}{$600 \mu \mathrm{g}$ bid $N=49$} & \multicolumn{2}{|c|}{$900 \mu \mathrm{g}$ bid $N=55$} & \multicolumn{2}{|c|}{ All patients $N=104$} \\
\hline & $\begin{array}{c}\text { Mean, } \\
\text { nmol/24 h }\end{array}$ & $\begin{array}{l}\text { Mean change from } \\
\text { baseline, \% (95\% Cl) }\end{array}$ & $\begin{array}{c}\text { Mean, } \\
\mathrm{nmol} / 24 \mathrm{~h}\end{array}$ & $\begin{array}{l}\text { Mean change from } \\
\text { baseline, \% (95\% Cl) }\end{array}$ & $\begin{array}{c}\text { Mean, } \\
\mathrm{nmol} / 24 \mathrm{~h}\end{array}$ & $\begin{array}{c}\text { Mean change from } \\
\text { baseline, \% }(95 \% \mathrm{Cl})\end{array}$ \\
\hline Baseline & 853.5 & - & 752.0 & - & 799.8 & - \\
\hline Week 12 & 120.9 & $-60.0(-71.8,-48.3)$ & 291.2 & $-34.1(-49.0,-19.2)$ & 221.6 & $-44.7(-54.9,-34.5)$ \\
\hline Week 24 & 113.5 & $-58.8(-72.4,-45.3)$ & 444.2 & $-24.1(-42.2,-6.1)$ & 286.0 & $-40.7(-52.6,-28.8)$ \\
\hline Week 48 & 108.8 & $-60.2(-77.1,-43.2)$ & 518.5 & $-23.1(-64.3,18.2)$ & 323.4 & $-40.7(-63.3,-18.2)$ \\
\hline
\end{tabular}

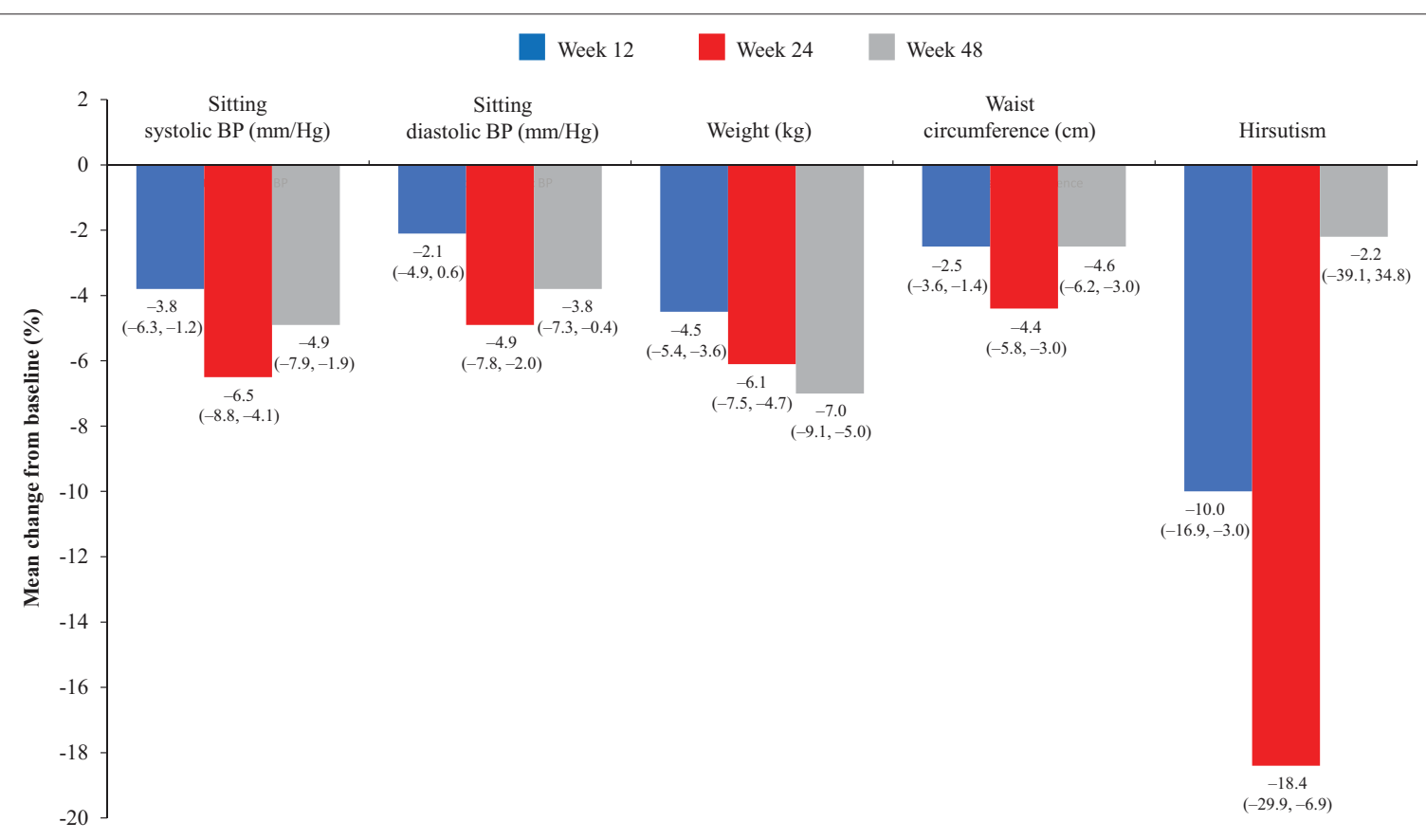

FIGURE 2 | Mean percentage change in signs and symptoms of hypercortisolism from baseline to weeks 12, 24, and 48 in the overall study population. Values in parentheses are two-sided $95 \%$ exact Cls.

therapy should be initiated as necessary (24). An ongoing Phase IV study is currently investigating the optimal management of pasireotide-associated hyperglycemia (clinicaltrials.gov, identifier: NCT02060383).

Treatment with somatostatin analogs is commonly associated with gallstone formation, although this rarely is symptomatic or requires surgery $(16,27)$. In our study, $29 \%$ of patients had cholelithiasis. Notably, none of these AEs required discontinuation of pasireotide, and only one necessitated surgical intervention. Gallbladder ultrasound is advised at regular intervals during pasireotide treatment (5), and cholecystectomy should be considered for symptomatic patients.

Our analysis shows that 48 and $43 \%$ of evaluable patients had normalized mUFC at weeks 24 (6 months) and 48 (12 months), respectively. It should be noted that many patients did not have evaluable mUFC measurements at all time points, and that a contributing factor to this was the stipulation in the study protocol that patients only received pasireotide as part of the study until the drug became commercially available in their respective countries. Considering normalization of mUFC in this study after imputation of last available mUFC assessments for patients who had discontinued/missing values, 40 and $35 \%$ of patients had mUFC $\leq$ ULN at weeks 24 and 48, respectively. In a Phase III study, pasireotide sc normalized UFC levels in 22 and 19\% of patients (including those who received a dose increase after 3 months' treatment) with Cushing's disease after 6 and 12 months' treatment, respectively (16). As such, results from our real-world study support those shown in a clinical trial setting, demonstrating that pasireotide is effective at normalizing mUFC levels in patients with Cushing's disease. Results from this real-world study are not directly comparable to those from the Phase III clinical trial because of differences in study design and analysis. Importantly, while the primary aim of the Phase III trial was to assess the efficacy of two doses of pasireotide sc (600 and $900 \mu \mathrm{g})$ after 6 months of treatment in patients with Cushing's disease, the main purpose of our study was to provide additional safety data on the use of pasireotide sc in a real-world setting. It is also important to note that it is not possible to directly compare 


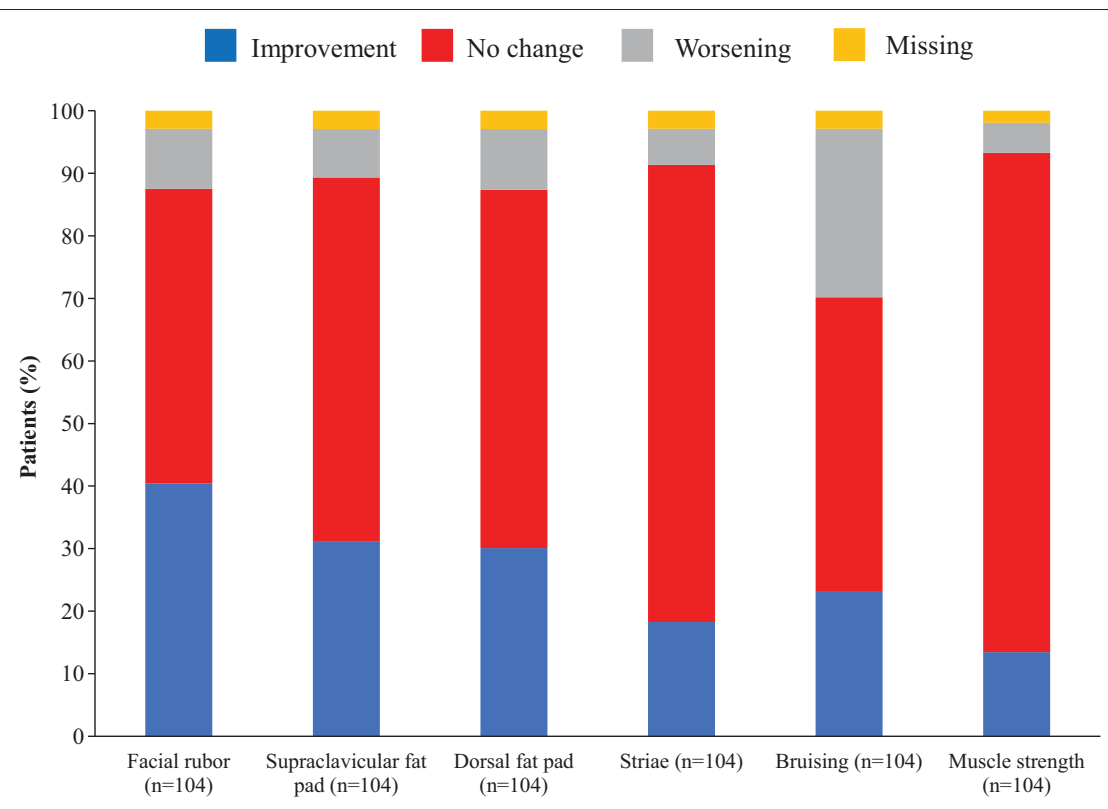

FIGURE 3 | Proportion of patients with improvement, no change or worsening of categorical signs of Cushing's disease from baseline to last post-baseline value in the overall study population.

mUFC response rates between studies. Unlike in the Phase III trial, which assessed response according to the intention-to-treat principle, the real-world nature of our study mandated that assessment of response was based on the number of patients who had evaluable UFC measurements at each time point. The benefits of our study lie within its observational nature. Realworld studies complement those performed in highly controlled trial settings by providing information on treatment practices and patient characteristics of populations typically excluded from clinical trials. Moreover, real-world studies are useful for identifying less frequent side effects of medications and for helping to guide treatment decisions.

In this study, the proportion of patients reported to have a normalized mUFC level at each time point was lower in the $900 \mu \mathrm{g}$ cohort than in the $600 \mu \mathrm{g}$ group. While it is important to note that this study was neither designed nor statistically powered to assess differences between dose cohorts, one possible explanation for the apparent difference in mUFC response rates between dose groups is that patients in the $600 \mu \mathrm{g}$ cohort may have had a lesser degree of hypercortisolism at baseline, as evidenced by the lower baseline mUFC level of this group compared with the $900 \mu \mathrm{g}$ group. Indeed, clinical trials of pasireotide have shown that normalization of mUFC is more likely to be achieved in patients with lower baseline/screening mUFC levels $(16,28)$. Furthermore, normalization of UFC is likely influenced by patients being able to receive a dose increase during the study. Therefore, the differences between dose groups in UFC normalization at time points should be interpreted with caution. Clinical signs and symptoms, as well as HRQoL, were also improved in our analysis, with the extent of change observed similar to that previously reported for pasireotide sc $(16,29)$.
Reductions in systolic and diastolic BP, waist circumference and weight, and improvements in QoL, were observed by week 12, with improvements sustained through to week 48, indicating continued therapeutic benefit during long-term treatment with pasireotide sc. Indeed, HRQoL impairment is a long-term multifactorial physical and psychosocial issue for patients with Cushing's disease that is known to persist even after achieving disease control (30). Although improvements in certain signs and symptoms, namely hirsutism, appeared to be dampened at week 48 compared with prior time points, this is likely related to the smaller number of women with evaluable measurements at this time compared with weeks 12 and 24.

Patients treated with pasireotide have been reported to derive significant clinical benefit even without normalization of UFC. In a subanalysis of the Phase III study of pasireotide sc in patients with Cushing's disease, patients without full control of UFC levels exhibited significant improvements in BP, weight, body mass index and waist circumference; notably, improvements in BP were greatest in patients who did not receive antihypertensive medications (29). Such patients may be suitable candidates for combination therapy.

Few studies have evaluated the efficacy and safety of pasireotide in real-world clinical practice. In the studies carried out in this setting to date, the results have supported the findings from prospective studies. In one study conducted in five Italian centers, $68 \%$ of patients with mild-moderate disease $(N=31)$ achieved a response to pasireotide (defined as normalization or near normalization of UFC $[<1.0-1.1 \times$ ULN $]$ ) after 6 months of treatment, which was accompanied by improvements in clinical signs and symptoms (19). The safety profile of pasireotide was consistent with that previously observed during 


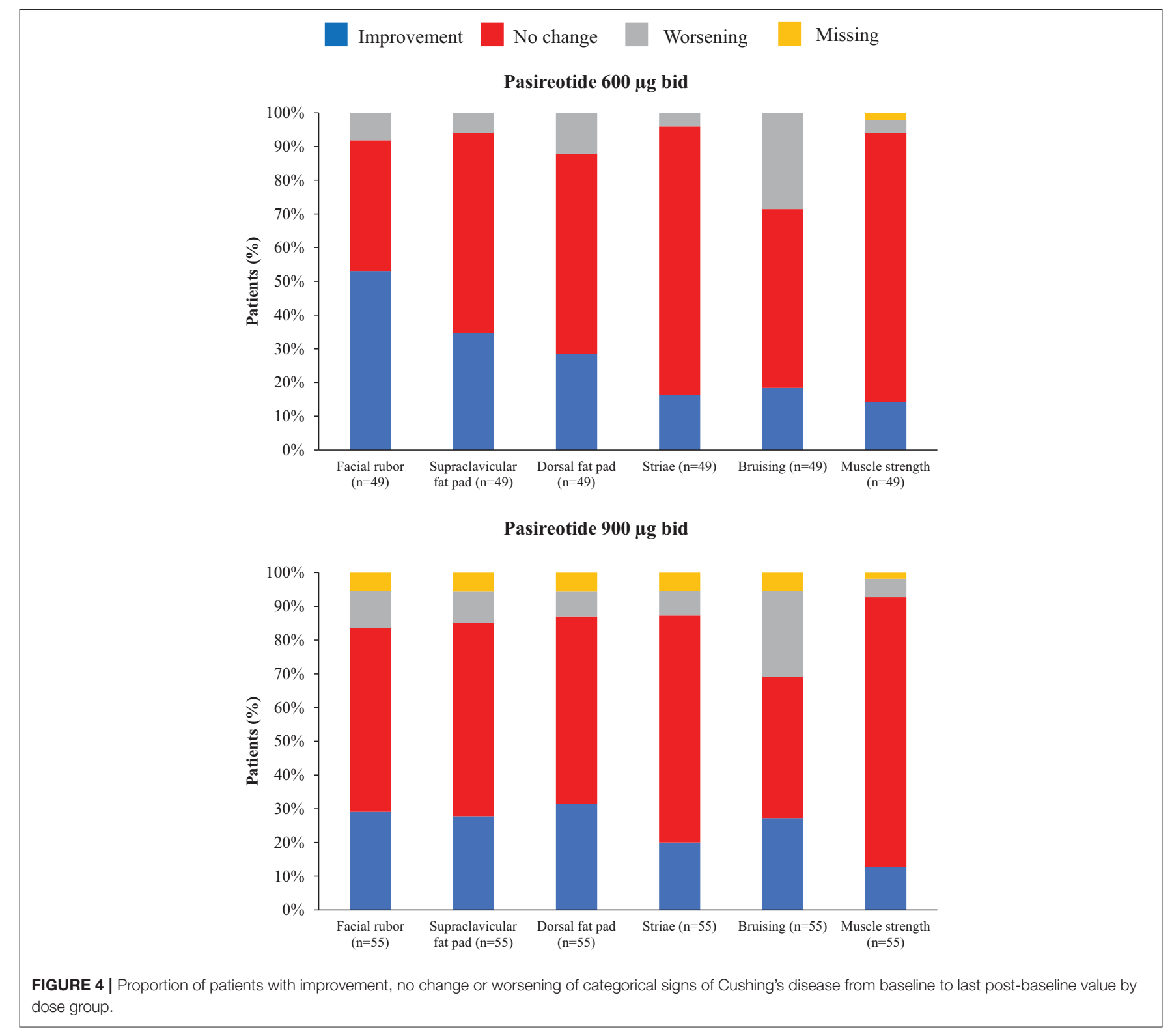

the Phase III study of pasireotide in Cushing's disease (16), with hyperglycemia a frequent ( $81 \%$ of patients) but manageable side effect (study goal of $\mathrm{HbA}_{1 \mathrm{c}}<7.5 \%$ achieved in $65 \%$ of patients). The efficacy of pasireotide has also been demonstrated in a small, 12-month, single-center study; all five patients who received pasireotide were biochemically controlled after 1 year of treatment, with four of these patients also maintaining normal glycemic control (17). The long-term efficacy of pasireotide has been demonstrated in another single-center study: $50 \%$ of patients $(N=20)$ treated with pasireotide sc for a median (range) of 9 (3-72) months had normalized mUFC at their last followup (18). Finally, another Italian multicenter study highlighted the potential cardioprotective effects of pasireotide treatment, with 12 months of treatment leading to significant reductions in cardiometabolic risk factors (20). While these real-world studies provide key insights into the use of pasireotide in clinical practice, they are limited by their small patient populations.

Several of the currently available medical therapies have demonstrated efficacy for the treatment of Cushing's disease in retrospective studies. In one study of 200 patients treated with ketoconazole, $49.0 \%$ of patients were reported to have attained control of UFC levels at last follow-up (31). Tolerability issues led to treatment withdrawal in $20.5 \%$ of patients, with hepatotoxicity ( $18.5 \%$ of patients reported increased liver enzyme levels) the main safety issue concerning this agent, which is reversible for some patients following treatment discontinuation (32). In a retrospective analysis of 195 patients with Cushing's disease, $\sim 64 \%$ of 38 patients treated with metyrapone achieved normalized UFC levels, with treatment generally well-tolerated and discontinuation (permanent or temporary) because of 
TABLE 9 | Mean change from baseline to weeks 12, 24, and 48 in continuous signs/symptoms of hypercortisolism, and quality of life, overall and by dose group.

\begin{tabular}{|c|c|c|c|}
\hline Clinical parameter & $\begin{array}{c}\text { Pasireotide } 600 \mu \mathrm{g} \text { bid } \\
N=49 \text { Mean, } \%(95 \% \mathrm{Cl})\end{array}$ & $\begin{array}{c}\text { Pasireotide } 900 \mu \mathrm{g} \text { bid } \\
N=55 \text { Mean, } \%(95 \% \mathrm{Cl})\end{array}$ & $\begin{array}{c}\text { All patients } N=104 \\
\text { Mean, } \%(95 \% \mathrm{Cl})\end{array}$ \\
\hline \multicolumn{4}{|l|}{ WEEK 12} \\
\hline Sitting SBP, mmHg & $-6.8(-10.3,-3.4)$ & $-1.4(-5.0,2.3)$ & $-3.8(-6.3,-1.2)$ \\
\hline Sitting DBP, mmHg & $-4.6(-8.9,-0.2)$ & $-0.2(-3.8,3.4)$ & $-2.1(-4.9,0.6)$ \\
\hline Weight, kg & $-4.2(-5.2,-3.1)$ & $-4.8(-6.2,-3.4)$ & $-4.5(-5.4,-3.6)$ \\
\hline Waist circumference, cm & $-2.0(-3.2,-0.7)$ & $-2.9(-4.7,-1.2)$ & $-2.5(-3.4,-1.4)$ \\
\hline Hirsutism (females only), Ferriman-Gallway score & $-12.2(-20.9,-3.7)$ & $-8.2(-19.0,2.6)$ & $-10.0(-16.9,-3.0)$ \\
\hline QoL, CushingQoL score & $21.3(7.4,35.2)$ & $100.8(37.6,164.0)$ & $67.1(30.0,104.3)$ \\
\hline \multicolumn{4}{|l|}{ WEEK 24} \\
\hline Sitting SBP, mmHg & $-7.4(-10.6,-4.3)$ & $-5.7(-9.2,-2.2)$ & $-6.5(-8.8,-4.1)$ \\
\hline Sitting DBP, mmHg & $-6.2(-8.8,-3.7)$ & $-3.8(-8.8,1.2)$ & $-4.9(-7.8,-2.0)$ \\
\hline Weight, kg & $-7.3(-9.2,-5.4)$ & $-5.2(-7.2,-3.1)$ & $-6.1(-7.5,-4.7)$ \\
\hline Waist circumference, $\mathrm{cm}$ & $-5.8(-8.0,-3.6)$ & $-3.1(-4.9,-1.7)$ & $-4.4(-5.8,-3.0)$ \\
\hline Hirsutism (females only), Ferriman-Gallway score & $-21.2(-35.5,-6.8)$ & $-16.2(-34.4,2.0)$ & $-18.4(-29.9,-6.9)$ \\
\hline QoL, CushingQoL score & $36.7(15.5,57.9)$ & $119.7(16.2,223.2)$ & $82.3(25.2,139.4)$ \\
\hline \multicolumn{4}{|l|}{ WEEK 48} \\
\hline Sitting SBP, mmHg & $-5.1(-8.9,-1.4)$ & $-4.7(-9.5,-0.0)$ & $-4.9(-7.9,-1.9)$ \\
\hline Sitting DBP, mmHg & $-3.3(-7.8,1.3)$ & $-4.3(-9.5,1.0)$ & $-3.8(-7.3,-0.4)$ \\
\hline Weight, kg & $-8.0(-11.0,-5.0)$ & $-6.3(-9.3,-3.3)$ & $-7.0(-9.1,-5.0)$ \\
\hline Waist circumference, cm & $-5.1(-7.6,-2.6)$ & $-4.1(-6.3,-2.0)$ & $-4.6(-6.2,-3.0)$ \\
\hline Hirsutism (females only), Ferriman-Gallway score & $-18.2(-34.7,-1.7)$ & $9.6(-55.8,75.0)$ & $-2.2(-39.1,34.8)$ \\
\hline QoL, CushingQoL score & $24.0(6.8,41.1)$ & $42.3(18.8,65.8)$ & $34.4(19.5,49.4)$ \\
\hline
\end{tabular}

DBP, diastolic blood pressure; SBP, systolic blood pressure.

AEs reported in 23\% of patients (33). Mifepristone has been shown to moderate the metabolic burden of Cushing's disease patients, as well as induce positive changes in clinical signs and symptoms, in an open-label, 24-week trial (34). Although adrenal insufficiency is a potential serious side effect of mifepristone treatment (35), it was rarely reported in the 24-week trial. Despite these agents showing efficacy in some patients with Cushing's disease, it is imperative that selection of medical therapy is tailored to the individual clinical situation (11), and for the treatment selected, careful monitoring for relevant AEs should be performed, with appropriate action taken should any arise. Several combinations of medical therapies have been used to treat patients with Cushing's disease, mostly in small retrospective studies $(8,12,15)$. One prospective study to date demonstrated how the addition of cabergoline and ketoconazole to pasireotide in a stepwise approach in patients biochemically uncontrolled on pasireotide alone increased the number of patients with normalized mUFC (36).

While the primary endpoint of this expanded-access study was to document the safety and tolerability of pasireotide sc, the analysis of efficacy was confounded by the nature of the study, whereby patients only received pasireotide as part of the study until the drug became commercially available in their respective countries, precluding evaluation of UFC normalization in many patients.

In conclusion, this is the first study to our knowledge to report detailed safety of pasireotide sc in a large, international population of patients with Cushing's disease in clinical practice. The findings from this study provide valuable insights into the use of pasireotide in the real world; pasireotide sc was generally tolerated, with no new safety signals identified. While hyperglycemia-related AEs were frequent, most were manageable, with $<6 \%$ of patients discontinuing because of these events. The efficacy data presented here demonstrate the effectiveness of pasireotide sc in real-world clinical practice.

\section{DATA AVAILABILITY}

Novartis is committed to sharing with qualified external researchers access to patient-level data and supporting clinical documents from eligible studies. These requests are reviewed and approved by an independent review panel on the basis of scientific merit. All data provided are anonymized to respect the privacy of patients who have participated in the trial, in line with applicable laws and regulations. This trial data availability is done according to the criteria and processes described at www. clinicalstudydatarequest.com.

\section{ETHICS STATEMENT}

This study was carried out in accordance with the recommendations of the Declaration of Helsinki with written informed consent from all subjects. All subjects gave written informed consent in accordance with the Declaration of Helsinki. The protocol was approved by the independent ethics committee 
or institutional review board for each participating center (Supplementary Appendix).

\section{AUTHOR'S NOTE}

The study was designed by the academic investigators and the sponsor, Novartis Pharma AG. Data were collected by investigators using Novartis' data management systems and analyzed by Novartis' statistical team. The academic investigators enrolled patients in the study. Writing, reviewing, amending of the manuscript the first draft was prepared by a medical writer funded by Novartis Pharmaceuticals Corporation.

\section{AUTHOR CONTRIBUTIONS}

All authors contributed to data interpretation. All the authors made the decision to submit the manuscript for publication and vouch for the accuracy and completeness of the data. FC performed the statistical and data analysis.

\section{REFERENCES}

1. Lacroix A, Feelders RA, Stratakis CA, Nieman LK. Cushing's syndrome. Lancet. (2015) 386:913-27. doi: 10.1016/S0140-6736(14)61375-1

2. Feelders RA, Pulgar SJ, Kempel A, Pereira AM. The burden of Cushing's disease: clinical and health-related quality of life aspects. Eur J Endocrinol. (2012) 167:311-26. doi: 10.1530/EJE-11-1095

3. Etxabe J, Vazquez JA. Morbidity and mortality in Cushing's disease: an epidemiological approach. Clin Endocrinol. (1994) 40:479-84. doi: 10.1111/j.1365-2265.1994.tb02486.x

4. Pivonello R, Isidori AM, De Martino MC, Newell-Price J, Biller BMK, Colao A. Complications of Cushing's syndrome: state of the art. Lancet Diabetes Endocrinol. (2016) 4:611-29. doi: 10.1016/S2213-8587(16)0 0086-3

5. Nieman LK, Biller BM, Findling JW, Murad MH, Newell-Price J, Savage $\mathrm{MO}$, et al. Treatment of Cushing's syndrome: an Endocrine Society clinical practice guideline. J Clin Endocrinol Metab. (2015) 100:2807-31. doi: $10.1210 /$ jc. $2015-1818$

6. Dekkers OM, Horváth-Puhó E, Jørgensen JO, Cannegieter SC, Ehrenstein V, Vandenbroucke JP, et al. Multisystem morbidity and mortality in Cushing's syndrome: a cohort study. J Clin Endocrinol Metab. (2013) 98:2277-84. doi: 10.1210/jc.2012-3582

7. Graversen D, Vestergaard P, Stochholm K, Gravholt CH, Jorgensen JO. Mortality in Cushing's syndrome: a systematic review and meta-analysis. Eur J Intern Med. (2012) 23:278-82. doi: 10.1016/j.ejim.2011.10.013

8. Pivonello R, De Leo M, Cozzolino A, Colao A. The treatment of Cushing's disease. Endocr Rev. (2015) 36:385-486. doi: 10.1210/er.2013-1048

9. Tritos NA, Biller BMK. Medical therapy for Cushing's syndrome in the twenty-first century. Endocrinol Metab Clin North Am. (2018) 47:427-40. doi: 10.1016/j.ecl.2018.01.006

10. Fleseriu M, Hamrahian AH, Hoffman AR, Kelly DF, Katznelson L. American association of clinical endocrinologists and American college of endocrinology disease state clinical review: diagnosis of recurrence in Cushing disease. Endocr Pract. (2016) 22:1436-48. doi: 10.4158/EP1615 12.DSCR

11. Biller BMK, Grossman AB, Stewart PM, Melmed S, Bertagna X, Bertherat J, et al. Treatment of adrenocorticotropin-dependent Cushing's syndrome: a consensus statement. J Clin Endocrinol Metab. (2008) 93:2454-62. doi: $10.1210 /$ jc.2007-2734

12. Fleseriu M, Castinetti F. Updates on the role of adrenal steroidogenesis inhibitors in Cushing's syndrome: a focus on novel therapies. Pituitary. (2016) 19:643-53. doi: 10.1007/s11102-016-0742-1

\section{FUNDING}

This study was funded by Novartis Pharma AG. Medical editorial assistance with this manuscript was funded by Novartis Pharmaceuticals Corporation.

\section{ACKNOWLEDGMENTS}

We thank the patients who participated in the trial, the site investigators and the study coordinators, as well as Thomas Walker Ph.D., Mudskipper Business Limited (funded by Novartis Pharmaceuticals Corporation), for providing medical editorial assistance.

\section{SUPPLEMENTARY MATERIAL}

The Supplementary Material for this article can be found online at: https://www.frontiersin.org/articles/10.3389/fendo. 2019.00436/full\#supplementary-material

13. de Bruin C, Feelders RA, Lamberts SW, Hofland LJ. Somatostatin and dopamine receptors as targets for medical treatment of Cushing's syndrome. Rev Endocr Metab Disord. (2009) 10:91-102. doi: 10.1007/s11154-0089082-4

14. Fleseriu M, Petersenn S. New avenues in the medical treatment of Cushing's disease: corticotroph tumor targeted therapy. J Neurooncol. (2013) 114:1-11. doi: 10.1007/s11060-013-1151-1

15. Langlois F, Chu J, Fleseriu M. Pituitary-directed therapies for Cushing's disease. Front Endocrinol. (2018) 9:164. doi: 10.3389/fendo.2018.00164

16. Colao A, Petersenn S, Newell-Price J, Findling JW, Gu F, Maldonado M, et al. A 12-month Phase 3 study of pasireotide in Cushing's disease. N Engl J Med. (2012) 366:914-24. doi: 10.1056/NEJMoa1105743

17. Yedinak CG, Hopkins S, Williams J, Ibrahim A, Cetas JS, Fleseriu M. Medical therapy with pasireotide in recurrent Cushing's disease: experience of patients treated for at least 1 year at a single center. Front Endocrinol. (2017) 8:35. doi: 10.3389/fendo.2017.00035

18. Trementino L, Michetti G, Angeletti A, Marcelli G, Concettoni C, Cardinaletti $\mathrm{C}$, et al. A single-center 10-year experience with pasireotide in Cushing's disease: patients' characteristics and outcome. Horm Metab Res. (2016) 48:290-8. doi: 10.1055/s-0042-101347

19. Pivonello R, Arnaldi G, Scaroni C, Giordano C, Cannavo S, Iacuaniello D, et al. The medical treatment with pasireotide in Cushing's disease: an Italian multicentre experience based on "real-world evidence." Endocrine. (2019) 64:657-72. doi: 10.1007/s12020-018-1818-7

20. Albani A, Ferraù F, Ciresi A, Pivonello R, Scaroni C, Iacuaniello D, et al. Pasireotide treatment reduces cardiometabolic risk in Cushing's disease patients: an Italian, multicenter study. Endocrine. (2018) 61:118-24. doi: 10.1007/s12020-018-1524-5

21. Novartis Pharma AG. Signifor Summary of Product Characteristics. (2016). Available online at: http://www.ema.europa.eu/docs/en_GB/document_ library/EPAR_-_Product_Information/human/002052/WC500128056.pdf (accessed October 2018).

22. National Cancer Institute. Common Terminology Criteria for Adverse Events v3.0. (2006). Available online at: https://ctep.cancer.gov/ protocolDevelopment/electronic_applications/docs/ctcaev3.pdf (accessed June, 2019).

23. Webb SM, Badia X, Barahona MJ, Colao A, Strasburger CJ, Tabarin A, et al. Evaluation of health-related quality of life in patients with Cushing's syndrome with a new questionnaire. Eur J Endocrinol. (2008) 158:623-30. doi: 10.1530/EJE-07-0762

24. Colao A, De Block C, Gaztambide MS, Kumar S, Seufert J, Casanueva FF. Managing hyperglycemia in patients with Cushing's disease treated with 
pasireotide: medical expert recommendations. Pituitary. (2014) 17:180-6. doi: 10.1007/s11102-013-0483-3

25. Silverstein JM. Hyperglycemia induced by pasireotide in patients with Cushing's disease or acromegaly. Pituitary. (2016) 19:536-43. doi: 10.1007/s11102-016-0734-1

26. Petersenn S, Salgado LR, Schopohl J, Portocarrero-Ortiz L, Arnaldi G, Lacroix A, et al. Long-term treatment of Cushing's disease with pasireotide: 5-year results from an open-label extension study of a Phase III trial. Endocrine. (2017) 57:156-65. doi: 10.1007/s12020-017-1316-3

27. Attanasio R, Mainolfi A, Grimaldi F, Cozzi R, Montini M, Carzaniga C, et al. Somatostatin analogs and gallstones: a retrospective survey on a large series of acromegalic patients. J Endocrinol Invest. (2008) 31:704-10. doi: 10.1007/BF03346419

28. Lacroix A, Gu F, Gallardo W, Pivonello R, Yu Y, Witek P, et al. Efficacy and safety of once-monthly pasireotide in Cushing's disease: a 12 month clinical trial. Lancet Diabetes Endocrinol. (2018) 6:17-26. doi: 10.1016/S2213-8587(17)30326-1

29. Pivonello R, Petersenn S, Newell-Price J, Findling J, Gu F, Maldonado M, et al. Pasireotide treatment significantly improves clinical signs and symptoms in patients with Cushing's disease: results from a Phase III study. Clin Endocrinol. (2014) 81:408-17. doi: 10.1111/cen.12431

30. Colao A, Cozzolino A, Pivonello R. Quality of life in patients with Cushing's disease: a modern approach. Clin Endocrinol. (2012) 76:776-7. doi: $10.1111 / j .1365-2265.2012 .04344 . x$

31. Castinetti F, Guignat L, Giraud P, Muller M, Kamenicky P, Drui D, et al. Ketoconazole in Cushing's disease: is it worth a try? J Clin Endocrinol Metab. (2014) 99:1623-30. doi: 10.1210/jc.2013-3628

32. Young J, Bertherat J, Vantyghem MC, Chabre O, Senoussi S, Chadarevian R, et al. Hepatic safety of ketoconazole in Cushing's syndrome: results of a compassionate use programme in France. Eur J Endocrinol. (2018) 178:44758. doi: 10.1530/EJE-17-0886

33. Daniel E, Aylwin S, Mustafa O, Ball S, Munir A, Boelaert K, et al. Effectiveness of metyrapone in treating Cushing's syndrome: a retrospective multicenter study in 195 patients. J Clin Endocrinol Metab. (2015) 100:414654. doi: 10.1210/jc.2015-2616
34. Fleseriu M, Biller BM, Findling JW, Molitch ME, Schteingart DE, Gross C. Mifepristone, a glucocorticoid receptor antagonist, produces clinical and metabolic benefits in patients with Cushing's syndrome. J Clin Endocrinol Metab. (2012) 97:2039-49. doi: 10.1210/jc.2011-3350

35. Castinetti F, Conte-Devolx B, Brue T. Medical treatment of Cushing's syndrome: glucocorticoid receptor antagonists and mifepristone. Neuroendocrinology. (2010) 92(Suppl. 1):125-30. doi: 10.1159/000314224

36. Feelders RA, de Bruin C, Pereira AM, Romijn JA, Netea-Maier RT, Hermus $\mathrm{AR}$, et al. Pasireotide alone or with cabergoline and ketoconazole in Cushing's disease. N Engl J Med. (2010) 362:1846-8. doi: 10.1056/NEJMc10 00094

Conflict of Interest Statement: MF has received grants to her university as a clinical investigator for Novartis, Millendo and Strongbridge Biopharma, as well as occasional scientific consulting fees from Novartis and Strongbridge Biopharma. $\mathrm{CI}$ is employed by Panda Medical Associates. LS and TM have received personal fees as clinical investigators for Novartis. RM and FC are full-time employees of Novartis Pharmaceuticals Corporation. The authors declare that this study received funding from Novartis. The funder designed the study with the academic investigators and analyzed the data, which were collected by the investigators using Novartis's data management systems. Writing, reviewing, and amending of the manuscript's first draft was carried out by a medical writer funded by Novartis Pharmaceuticals Corporation.

The remaining author declares that the research was conducted in the absence of any commercial or financial relationships that could be construed as a potential conflict of interest.

Copyright (๑) 2019 Fleseriu, Iweha, Salgado, Mazzuco, Campigotto, Maamari and Limumpornpetch. This is an open-access article distributed under the terms of the Creative Commons Attribution License (CC BY). The use, distribution or reproduction in other forums is permitted, provided the original author(s) and the copyright owner(s) are credited and that the original publication in this journal is cited, in accordance with accepted academic practice. No use, distribution or reproduction is permitted which does not comply with these terms. 